\title{
Introduction: Peripheral Nerve Surgery-Biology, Entrapment, and Injuries
}

\author{
Allan H. Friedman, W. Jeffrey Elias, and Rajiv Midha \\ Duke University Medical Center, Durham, North Carolina; Department of Neurosurgery, \\ University of Virginia Health System; and Division of Neurosurgery, University of Calgary, Canada
}

$\mathrm{S}$ URGERY aimed at repairing damaged peripheral nerves has a long history. Refuting the timehonored nihilism of Hippocrates and Galen that an injured nerve cannot regain function, a few adventurous medieval surgeons attempted to repair severed nerves ${ }^{6,8}$ However, the ability of a peripheral nerve repair to restore function was not generally accepted until $1800 .{ }^{1,4}$ Neurosurgeons, beginning with Harvey Cushing, have had an interest in repairing damaged peripheral nerves. ${ }^{2}$ Significant progress in the treatment of peripheral nerve injuries resulted from experience with the numerous injuries that occurred during World Wars I and II. ${ }^{3,7,12}$ Surgeons steadily defined the anatomy of peripheral nerves and developed techniques for decompressing and repairing peripheral nerves. ${ }^{9}, 11$ Kline and Dejonge ${ }^{5}$ developed an intraoperative electrophysiological technique for detecting axons regenerating across a damaged segment of nerve. In the second 2 decades of the 20th century, distal nerve transfers were rediscovered whereby the proximal end of a less essential nerve is used to reinnervate the distal end of a nerve, providing a more vital function. ${ }^{10}$

Even with the aid of the best of surgical techniques, peripheral nerve surgery seems to have hit an impasse. Our present techniques have failed to yield good results in several common circumstances. Repair of a severed mixed motor and sensory nerves, such as the ulnar or median nerve, on average yields less than perfect results. Repair of nerves, that are distant from their target, such as the lower trunk of the brachial plexus, is unlikely to restore useful function. Similarly, with longer nerve gaps, successful surgical repairs are less likely.

This edition of Neurosurgical Focus presents some of the most recent progress in peripheral nerve surgery. We begin with basic science discoveries, which may translate into solutions for the problems in peripheral nerve surgery. Using the technique of molecular biology we are able to go beyond describing nerve regeneration and begin to understand and manipulate the biology governing the regeneration. Dr. Gordon reviews the role of neurotrophic factors in stimulating and guiding nerve regeneration. Drs. Midha and Levi review the uses and limitations of stem cells and Schwann cells in stimulating the regeneration of peripheral nerves. Dr. Spinner describes the specification for a synthetic conduit that would span the gap between the 2 ends of a divided nerve, and Dr. Gupta reviews the pathophysiology of entrapment neuropathy. Dr. Rochkind reports on his extensive experience with using phototherapy to stimulate peripheral nerve growth.

There are some clinical problems related to peripheral nerve injury or entrapment that have yet to be clearly defined. Dr. Filler outlines his experience in diagnosing and treating pudendal nerve entrapments. Dr. Spinner ex- pands his hypothesis of the origin of intraneural ganglia to account for cysts involving the nerves of the upper extremities. He goes on to describe an engineering model for intraneural ganglia. Dr. Brown reviews the Washington University experience with various innovative distal nerve transfers for the treatment of nerve injuries. Dr. Koenig reports on the status of using high-resolution ultrasonography to evaluate an injured or entrapped nerve. We are always on the lookout for new therapies, and Dr. Winfree reports his expertise using nerve transfers to treat a single patient with a lower thoracic spinal cord injury.

Nerve surgeons have made continual progress in restoring function and reducing pain in those who have suffered a peripheral nerve injury. Our present techniques seem inadequate to restore function following many proximal nerve injuries. Innovative techniques, such as nerve transfers, provide only a partial solution. It is our hope that advances in molecular and cell biology will reveal several mechanisms of nerve regeneration and nerve guidance that can be manipulated to greatly improve our ability to repair damaged nerves.

\section{References}

1. Cruickshank W: Experiments on the nerves, particularly on their reproduction, and on the spinal marrow of living animals. Philos Trans R Soc Lond 85:177-189, 1795

2. Cushing H: The surgical treatment of facial paralysis by nerve anastamosis. Ann Surg 37:641-669, 1903

3. Elsberg CA: Technic of nerve suture and nerve grafting. JAMA 73:1422-1427, 1919

4. Haighton J: An experimental inquiry concerning the repro- 
duction of nerves. Philos Trans R Soc Lond 85:190-201, 1795

5. Kline DG, Dejonge BR: Evoked potentials to evaluate peripheral nerve injuries. Surg Gynecol Obstet 127:1239-1248, 1968

6. Lanfranco: Science of Cirurgie. Early English Text Society. London: Paul, Trench, Trübner, 1894

7. Langley JN, Hashimoto M: On the suture of separate nerve bundles in a nerve trunk and on internal nerve plexuses. $\mathbf{J}$ Physiol 51:318-346, 1917

8. Leonard of Bertapaglia: On Nerve Injuries and Skull Fractures. Ladenheim, JC (ed and trans). New York: Futura Publishing Company, 1989

9. Millesi $\mathrm{H}$ : Indications and techniques of nerve grafting, in
Gelberman RH (ed): Operative Nerve Repair and Reconstruction, Vol 1. Philadelphia: JB Lippincott Company, 1991, pp 525-5431

10. Oberlin C, Beal D, Leechavengvongs S, Salon A, Dauge MC, Sarcy JJ: Nerve transfer to biceps muscle using a part of ulnar nerve for C5-C6 avulsion of the brachial plexus: anatomical study and report of four cases. J Hand Surg [Am] 19:232237, 1994.

11. Sunderland S: Nerve and Nerve Injuries. Edinburgh: Churchill-Livingstone, 1978

12. Woodhall B, Beebe G: Peripheral Nerve Regeneration: A Follow-Up Study of 3,656 World War II Injuries. Washington DC: US Government Printing Office, 1956 